\title{
Neonatal bacterial meningitis in Tikur Anbessa Specialized Hospital, Ethiopia: a 10-year retrospective review
}

\author{
Melese Abate Reta ${ }^{1 *}$ and Tamrat Abebe Zeleke ${ }^{2}$
}

\begin{abstract}
Background: Bacterial meningitis is still a major public health threat in developing countries. It is an overwhelming infection with a high morbidity and mortality rate, especially in neonates. The aim of this study was to determine the prevalence and etiological agents that cause bacterial neonatal meningitis at Tikur Anbessa Specialized Hospital (TASH).

Methods: This is a retrospective analysis of 1189 cerebrospinal fluid (CSF) specimens submitted to the bacteriology laboratory of TASH for culture from 2001 to 2010. All newborns younger than 29 days old that were suspected for bacterial meningitis cases were included in the study.

Results: Based on CSF culture, 56 newborns were identified as having bacterial meningitis from a total of 1189 suspected cases. The overall prevalence of neonatal bacterial meningitis from the total suspected cases was $4.7 \%$. The organisms identified and their prevalence rates were Streptococcus pneumoniae 13 (23\%), Escherichia coli 9 (16\%), Acinetobacter 7 (13\%), Neisseria meningitides 5 (9\%), Klebsiella spp. 5 (9\%), Staphylococcus aureus 3 (5\%) and Streptococcus pyogen $3(5 \%)$. There were two (4\%) cases each that was caused by Coagulase-Negative-Staphylococcus and Non-Group-A-Streptococcus, while 1 (2\%) caused by Haemophilus influenzae. S. pneumoniae was the main etiological agent identified from CSF culture. The male to female ratio was 1:0.88 (53\% were male). The birth weights of 34 (61\%) patients were under $2500 \mathrm{~g}$, and 22 (39\%) patients had normal birth weights. Twenty-seven (48\%) were early onset cases, and 29 (52\%) were late-onset.
\end{abstract}

Conclusion: Streptococcus pneumoniae and Escherichia coli were the two main etiological agents for neonatal bacterial meningitis infection in the study area.

Keywords: Neonates, Bacterial meningitis, Streptococcus pneumonia, E. coli

\section{Background}

Acute bacterial meningitis occurs more commonly during the first month of life than any other subsequent period and it is associated with high morbidity and mortality. Neonatal meningitis is an illness characterized as a result of infection of the meninges and it typically happens between birth and the first 28 days of life (Mohammad et al. 2010; Luzia et al. 2007; Delouvois et al. 1991). Neonatal meningitis is an important cause of morbidity

\footnotetext{
*Correspondence: melese1985@gmail.com

1 Department of Medical Laboratory Science, Faculty of Health Science, Woldia University, P.O. Box 400, Woldia, Ethiopia

Full list of author information is available at the end of the article
}

in sub-Saharan Africa and requires urgent empiric treatment with parenteral administered antibiotics (Olivia et al. 2014).

The incidence of neonatal meningitis in western countries varies from 0.2 to 0.5 cases per 1000 live births but much higher rates of 1.1-1.9 per 1000 have been reported from developing countries (Laving et al. 2003). The mortality varies based on the treatment, with survival rates of $17-29 \%$ and with complications rates of 15-68\% (Luzia et al. 2007). Two-thirds of meningitis deaths in low income countries occur among children under 15 years of age (Meenakshi et al. 2009). 
The causative agents of neonatal bacterial meningitis are different geographically. In most developed countries the main causative agents for neonatal bacterial meningitis isolated from cerebrospinal fluid (CSF) are Group $B$ Streptococcus (GBS), E. coli, Listeria monocytogenes and S. pneumonia (Harvey et al. 1999; Delouvois et al. 1991; Pong and Bradley 1999). Infections in the neonatal period are 'early onset' (implying vertical transmission) when frequently isolated bacteria include GBS, E. coli and $L$. monocytogenes, and 'late onset' (implying nosocomial or community acquired infection). The microorganism spectrum responsible for neonatal meningitis in developing countries is different. The Reasons for this may include genetic differences in immune response and possibly geographic differences in laboratory techniques for pathogen isolation and reporting and they are also influenced by maternal and infant risk factors, and prevention and treatment strategies of the country (Bozena et al. 2005; Osrin et al. 2004; Heath et al. 2003). The bacteria causing neonatal meningitis not only vary between different countries, but also show temporal changes within the same country (Mohammad et al. 2010). In developed countries infection with gram-negative bacilli accounts for $30-40 \%$ of meningitis case (Dawson et al. 1999). The disease is often more severe with gram-negative bacteria than with gram-positive bacteria with higher rates of both mortality and morbidity. Neonatal and maternal risk factors for developing neonatal meningitis include low birth weight, prematurity, premature ruptures of membranes, maternal chorioamnionitis and low socioeconomic status (Polin and Harris 2001; Osrin et al. 2004). The newborn that is particularly susceptible to infection as the immature immune system is deficient in humoral and cellular immune responses (Saleem et al. 2014; Pablo et al. 2007).

Signs of meningitis are often subtle in the neonate; thus, meningitis must be diagnosed by examination of CSF. Culturing the CSF is a proven test for demonstration of bacterial meningitis (Mohammad et al. 2010). Other tests, including the evaluation of glucose, protein, and leukocyte levels in the CSF can help to diagnose bacterial meningitis. However, Harmony et al. (2006) have stated that neonates with bacterial meningitis cannot be diagnosed accurately with CSF glucose or protein evaluation because of lack of specificity due to a wide distribution of normal values in this age group (Matthijs et al. 2010). Our study was carried out by identifying etiological agents and assessing the association between gestational age, birth weight, onset type and bacterial meningitis.

\section{Methods}

\section{Study population}

The study was carried out at the Tikur Anbessa Specialized Hospital (TASH), Ethiopia. The records of all neonates admitted to the general wards of the hospital from 2001 to 2010 were retrieved from the records department. All neonates suspected with bacterial meningitis (BM) infection cases were first identified from the bacteriology laboratory registers. The neonatal period was defined as that time from birth to 28 days of age. A pre-coded data sheet was used to extract information from each record. The patient was identified by hospital inpatient number and study number given in consecutive sequence. The following data were abstracted from the charts: Gender, birth weight, gestational age, type of infections and isolated organism. The data were analyzed on the basis of gender, type of infection [early-onset infection ( $\leq 7$ days), late-onset infection ( $>7$ days) and gestational age of the neonates]. Infants were categorized according to their birth weight into three groups: Normal weight ( $\geq 2500 \mathrm{~g})$, low birth weight (LBW) (1500-2499 g) and very low birth weight (VLBW) (1000-1499 g). Gestational age was recorded as term ( $\geq 37$ weeks) or preterm ( $<37$ weeks), and the information on mean of bodyweight, mean of gestational age and isolation of bacterial agents was recorded.

\section{Laboratory methods}

Approximately $0.5-1.0 \mathrm{ml}$ of CSF obtained aseptically via a lumbar puncture was collected in two specimen bottles and taken immediately to department of bacteriology laboratory, TASH. The sediment of centrifuged CSF from the sterile bottle was inoculated using a sterile loop onto chocolate, blood agar and MacConkey's agar plates (HiMedia, Mumbai, India) and incubated at $35-37^{\circ} \mathrm{C}$ overnight in candle extinction jars to provide $5-8 \%$ carbon dioxide. The plates read every $24 \mathrm{~h}$ for 3 days. In case of a growth, the isolates would be processed and identified by standard bacteriological techniques. Cases were defined as meningitis if the CSF culture was positive for aerobic bacteria.

\section{Ethical considerations}

This being a retrospective study, ethical considerations was fulfilled by obtaining permission from the ethics and research committee of the Hospital. Thereafter inpatient registration number was used to identify the participants and not names; hence, this ensures confidentiality.

\section{Results}

\section{Characteristics of study population}

During the 10 year period considering this retrospective study 1189 neonate patients with suspected bacterial meningitis were examined using CSF culture in bacteriology laboratory at TASH. Six hundred thirty-two (53\%) were male, while 557 (47\%) were female; making male to female ratio of 1:0.88. The results of this study indicated 
that $533(45 \%)$ suspected cases of neonatal bacterial meningitis were late onset and 656 (55\%) were early onset. Three hundred fourteen of the 533 early-onset cases and 352 of the 656 late-onset cases weighed under $2500 \mathrm{~g}$. The mean birth weight of the neonates with $\mathrm{BM}$ suspected case was $2229 \mathrm{~g}$ (range: $1120-4100 \mathrm{~g}$ ), of which 422 (35\%) had normal birth weight, 614 (52\%) had LBW and $153(13 \%)$ had VLBW. According to the gestational age, $601(51 \%)$ suspected cases were preterm and 588 (49\%) cases were term (Table 1 ).

\section{Bacterial culture data}

Of the total 56 positive cases, the bacteria identified and their prevalence rates were S. pneumoniae 13 (23\%), E. coli 9 (16\%), Acinetobacter 7 (13\%), N. meningitidis 5 (9\%), Klebsiella spp. 5 (9\%), S. aureus $3(5 \%)$ and S. pyogen $3(5 \%)$. There were two (4\%) cases each that was caused by Coag. Negative-Staphylococcus, Non-Group-A-Streptococcus; while 1 (2\%) were caused by $H$. influenzae. The main etiological agent identified from CSF culture was $S$. pneumoniae. Nine percent of S. pneumoniae cases were isolated from LBW and VLBW neonates. The major causative agents for neonatal meningitis cases identified were isolated from newborns with LBW and VLBW (61\%) (Table 2).

\section{Year trends of bacterial meningitis cases of neonate patients}

The incidence of neonatal bacterial meningitis cases in each year revealed virtually similar isolation rate except

Table 1 Gender, types of infection, gestational age and birth weight of neonates diagnosed with neonatal bacterial meningitis suspected cases

\begin{tabular}{lcc}
\hline Variables & Frequency & Percent \\
\hline Gender & & \\
Male & 632 & 53 \\
Female & 557 & 47 \\
Total & 1189 & 100 \\
Type of infection & & \\
$\quad$ Early onset & 533 & 45 \\
Late onset & 656 & 55 \\
Total & 1189 & 100 \\
Gestational age of neonates & & \\
$\quad$ Preterm & 601 & 51 \\
Term & 588 & 49 \\
Total & 1189 & 100 \\
Birth weight of neonates & & 44 \\
$\geq 2500 \mathrm{~g}$ & 523 & 56 \\
$<2500 \mathrm{~g}$ & 666 & 100 \\
Total & 1189 & \\
\hline
\end{tabular}

no positive cases were identified in the year 2002, and large number of BM suspected cases have been admitted in the year 2010. Twelve (7.6\%) of bacterial pathogens were isolated only in the year 2001 (Fig. 1).

\section{Discussion}

The result of this study revealed that $S$. pneumoniae and $E$. coli were the two main etiological agents for neonatal bacterial meningitis infections at TASH. In most cases neonatal meningitis results from bacteremia (Hristeva et al. 1993; Synnott et al. 1994). In our study, the overall prevalence of bacterial meningitis infection among suspected cases of neonates in the 10 years review was (4.7\%) which is higher than the previous hospital population-based retrospective study on neonatal bacterial meningitis conducted in Addis Ababa, with an overall prevalence of 1.37 per 1000 live births (Gebremariam 1998). The difference might be due to the improvement of the laboratory to increase the chance of isolation of the bacteria during appropriate culturing techniques. In contrast to our finding very high isolation rates of neonatal bacterial meningitis was reported from Kenya which was 17.9\% (Laving et al. 2003), in Thailand 12.5\% (Chotpitayasunondh 1994), Australia 9.2\% (May et al. 2005) and Wichita 8.4\% (Michael and Anne 1985).

In this study the major organisms responsible for neonatal bacterial meningitis were S. pneumonia 13 (23\%), E. coli 9 (16\%), Acinetobacter 7 (13\%), N. meningitidis (9\%), Klebsiella spp. 5 (9\%), S. aureus 3 (5\%), S. pyogen $3(5 \%)$, Coagulase-Negative-Staphylococcus (4\%), Non-GroupA-Streptococcus (4\%), while 1 (2\%) caused by $H$. influenzae. In this study the main etiological agent identified from CSF culture was S. pneumoniae. A large scale world health organization (WHO) study conducted in various countries of meningitis belt including Ethiopia has documented similar patterns with $S$. pneumoniae being the most common organism. It was identified in $26 \%$ of the cases. S. pyogenes $(20 \%)$ and E. coli $(18 \%)$ were the other common organisms (WHO 1999). S. pneumoniae, GBS, E. coli and non-typhoidal Salmonella species appear to predominate in East Africa (Olivia et al. 2014). However, the report from Addis Ababa revealed that the common causative organisms for neonatal meningitis were Klebsiella pneumoniae, E. coli and Enterobacter spp. which together accounted for $67 \%$ of all CSF isolates (Gebremariam 1998). Other studies documented that K. pneumonia was the common causative organisms for neonatal bacterial meningitis; Jordan 40\% (Daoud et al. 1996), Iran 35.5\% (Mohammad et al. 2010), Saudi Arabia (31\%) (AlHarthi et al. 2000). However, other study from Australia (Francis and Gilbert 1992), Trinidad (Ali 1995), London (Heath et al. 2003; Delouvois et al. 1991) and Canada (Stevens et al. 2003) reported that GBS and E. coli were 
Table 2 Frequency of isolated bacteria in neonates with bacterial meningitis according to birth weight, onset type, and gestational age

\begin{tabular}{|c|c|c|c|c|c|c|}
\hline \multirow{2}{*}{$\begin{array}{l}\text { Organisms found in } \\
\text { CSF culture }\end{array}$} & \multicolumn{2}{|c|}{ Birth weight } & \multicolumn{2}{|c|}{ Onset type } & \multicolumn{2}{|c|}{ Gestational age } \\
\hline & $\begin{array}{l}\text { LBW } \\
<2500 \mathrm{~g} \\
\mathrm{n}(\%)\end{array}$ & $\begin{array}{l}\text { NBW } \\
\geq 2500 \mathrm{~g} \\
\mathrm{n}(\%)\end{array}$ & $\begin{array}{l}\text { Early } \\
\text { n (\%) }\end{array}$ & $\begin{array}{l}\text { Late } \\
\text { n (\%) }\end{array}$ & $\begin{array}{l}\text { Preterm } \\
\text { n (\%) }\end{array}$ & $\begin{array}{l}\text { Term } \\
\text { n (\%) }\end{array}$ \\
\hline No bacterial growth & $632(95)$ & $501(96)$ & $506(95)$ & $627(96)$ & $578(96)$ & $555(94)$ \\
\hline Klebsiella spp. & $3(0.5)$ & $2(0.4)$ & $3(0.6)$ & $2(0.3)$ & $3(0.5)$ & $2(0.3)$ \\
\hline S.pneumoniae & $5(0.8)$ & $8(1.5)$ & $6(1.1)$ & $7(1.1)$ & $4(0.7)$ & $9(1.5)$ \\
\hline S.pyogen & $1(0.2)$ & $2(0.4)$ & $1(0.2)$ & $2(0.3)$ & $1(0.2)$ & $2(0.3)$ \\
\hline S. aureus & $2(0.3)$ & $1(0.2)$ & $2(0.4)$ & $1(0.2)$ & $1(0.2)$ & $2(0.3)$ \\
\hline E. coli & $6(0.9)$ & $3(0.6)$ & $4(0.8)$ & $5(0.8)$ & $3(0.5)$ & $6(1)$ \\
\hline Acinetobacter & $7(1.1)$ & $0(0)$ & $7(1.3)$ & $0(0)$ & $5(0.8)$ & $2(0.3)$ \\
\hline N. meningitidis & $3(0.5)$ & $2(0.4)$ & $1(0.2)$ & $4(0.6)$ & $1(0.2)$ & $4(0.7)$ \\
\hline H. influenzae & $0(0)$ & $1(0.2)$ & $0(0)$ & $1(0.2)$ & $0(0)$ & $1(0.2)$ \\
\hline Coag. Negative-Staph & $0(0)$ & $2(0.4)$ & $0(0)$ & $2(0.3)$ & $1(0.2)$ & $1(0.2)$ \\
\hline Non-Group-A-Strep & $2(0.3)$ & $0(0)$ & $1(0.2)$ & $1(0.2)$ & $1(0.2)$ & $1(0.2)$ \\
\hline Salmonella & $2(0.3)$ & $0(0)$ & $0(0)$ & $2(0.3)$ & $2(0.3)$ & $0(0)$ \\
\hline Others & $3(0.5)$ & $1(0.2)$ & $2(0.4)$ & $2(0.3)$ & $1(0.2)$ & $3(0.5)$ \\
\hline Total positive & $34(5.1)$ & $22(4.2)$ & $27(5.1)$ & $29(4.4)$ & $23(3.8)$ & $33(5.6)$ \\
\hline Total & $666(100)$ & $523(100)$ & $533(100)$ & $656(100)$ & $601(100)$ & $588(100)$ \\
\hline
\end{tabular}

CSF cerebrospinal fluid, $L B W$ low birth weight, $N B W$ normal birth weight

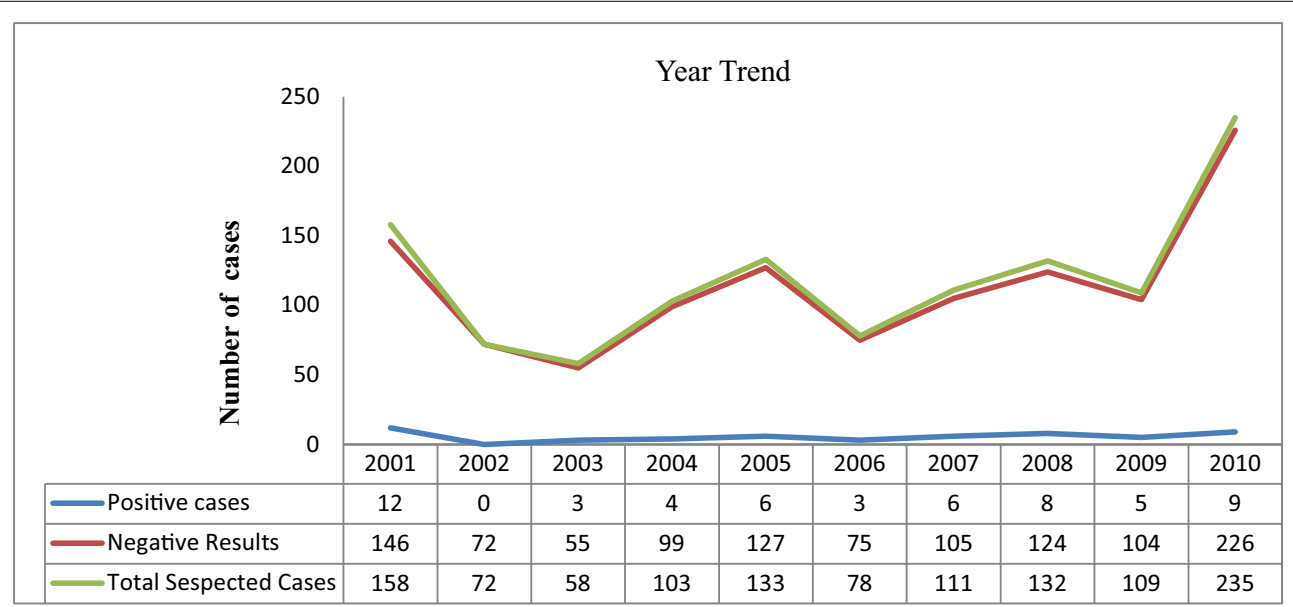

Fig. 1 Year trends of neonatal bacterial meningitis infections isolated from CSF culture

the major etiological agents for neonatal BM infection. In developing countries, $G B S$ appears to be much less frequent (Heath et al. 2003). In our study no case of GBS meningitis was identified; probably this organism may be rare in Ethiopia or perhaps the frequent use of ampicillin in suspected cases of neonatal infection could have stifled the isolation rate of this organism.

In our study $E$. coli was the second most common pathogen of neonatal bacterial meningitis accounted $16 \%$.
A Comparable study, Mohammad et al. (2010) in Iran reported that about $9.6 \%$ of neonatal meningitis cases were due to $E$. coli. This finding reveals that the etiological agents responsible for neonatal bacterial meningitis were slightly evenly distributed between early and lateonset meningitis, and among term and preterm newborns. In contrast to this, a study conducted in India (Ali 1995), London (Delouvois et al. 1991), Oxford (Hristeva et al. 1993) reported that $G B S$ was common in early onset 
meningitis infections. In North America and Europe, common etiological agents for early-onset neonatal sepsis are GBS, L. monocytogenes and E. coli and those of late-onset sepsis include Coagulase-Negative-Staphylococcus, Klebsiella sp. and E. coli (Hristeva et al. 1993; Synnott et al. 1994).

In our study most cases of BM with either early- or lateonset infection occurred in LBW or VLBW newborns. Thus, as in other reports (Grupo de Hospitales Castrillo 2002; Berman and Banker 1996) birth weight appears to be an important risk factor for acquisition of BM among neonates. In our study, 29 (52\%) neonates with BM had late-onset infection, whereas Chang et al. (2000) reported that from 85 patients, 51 (60\%) were younger than 7 days old. Similarly, findings documented from Nigeria (Airede et al. 2008), Australia (Francis and Gilbert 1992), Trinidad (Ali 1995), Brazil (Luzia et al. 2007), Jordan (Daoud et al. 1996) and Oxford (Hristeva et al. 1993) indicated that low birth weight showed higher risk of neonatal bacterial meningitis and was significantly more likely in the preterm $(p<0.05)$. There is evidence to suggest that meningitis in preterm low birth weight and sickly babies is caused by organisms, usually from the maternal genital tracts (Delouvois 1994). Although advanced neonatal care enables us to save even the most preterm neonates, the very interventions sustaining those who are hospitalized concurrently expose them to serious infections due to common nosocomial pathogens (Elizabeth et al. 2013).

The highest burden of bacterial meningitis occurs in an area of sub-Saharan Africa known as the "meningitis belt". This area is characterized by high prevalence of bacterial meningitis (Arslan 2012). Located on the eastern part of meningitis belt, Ethiopia is one of the countries which are most affected with bacterial meningitis (WHO 1999). Marked seasonal fluctuations occur in the prevalence of meningococcal meningitis which rises during the dry season from December to June with incidence as high as 1000 cases per 100,000 populations during an epidemic (Mueller and Gessner 2009). The incidence then falls steeply on the arrival of the rainy season. In this study the incidence of neonatal bacterial meningitis cases in the 10 years trend showed similar isolation rate except that no cases were identified in the year 2002.

In conclusion, we found that S. pneumoniae and E. coli were the two main etiological agents of neonatal bacterial meningitis during the 10 years review and the major causative agents for neonatal meningitis cases identified were isolated from newborns with LBW and VLBW.

This survey data had clinical input for the hospital, local health authority as well as for regional health bureau to implement appropriate meningitis surveillance against this invasive bacterial disease.
Authors' contributions

Both authors read and approved the final manuscript.

\section{Author details}

${ }^{1}$ Department of Medical Laboratory Science, Faculty of Health Science, Woldia University, P.O. Box 400, Woldia, Ethiopia. ${ }^{2}$ Department of Microbiology, Immunology and Parasitology, School of Medicine, Addis Ababa University, Addis Ababa, Ethiopia.

\section{Acknowledgements}

We are most sincerely grateful to Addis Ababa University for funding this research project, TASH bacteriology laboratory department for neonates BM laboratory result observation and Department of Pediatrics and Child Health for the permission to see patients' medical record profile.

\section{Competing interests}

The authors declare that they have no competing interests.

Received: 8 June 2016 Accepted: 8 November 2016

Published online: 14 November 2016

\section{References}

Airede KL, Adeyemi O, Ibrahim T (2008) Neonatal bacterial meningitis and dexamethasone adjunctive usage in Nigeria. Niger J Clin Pract 11(3):235-245

Al-Harthi AA, Dagriri KA, Asindi AA, Bello CS (2000) Neonatal meningitis. Saudi Med J 21(6):550-553

Ali Z (1995) Neonatal meningitis: a 3-year's retrospective study at the Mount Hope Women's Hospital, Trinidad, West Indies. JTrop Pediatr 41(2):109111. doi:10.1093/tropej/41.2.109

Arslan A (2012) Etiology of bacterial meningitis in Ethiopia, 2007-2011: a retrospective study. Faculty of Medicine, University of Oslo. Master thesis, pp 1-95

Berman PH, Banker BQ (1996) Neonatal meningitis: a clinical and pathological study of 29 cases. Pediatrics 38:6-24

Bozena K, Joachim F, Jacques S, Gerd P, Riccardo P, Ralf E et al (2005) Use of diagnostic microarrays for determination of virulence gene patterns of E. coli K1, a major cause of neonatal meningitis. J Clin Microbiol 43:1024-1031

Chang CHY, Chiu NC, Li WC, Huang FY (2000) Characteristics of neonatal bacterial meningitis in a teaching hospital in Taiwan from 1984-1997. J Microbiol Immunol Infect 33:100-104

Chotpitayasunondh T (1994) Bacterial meningitis in children: etiology and clinical features 11-years review of 618 cases. South East Asian J Trop Med Public Health 25(1):107-115

Daoud AS, Al-Sheyyab M, Abu-Ekteish F, Obeidat A, Ali AA, El-Shanti H (1996) Neonatal meningitis in Northern Jordan. JTrop Pediatr 42(5):267-270

Dawson KG, Emerson JC, Burns JL (1999) Fifteen years of experience with bacterial meningitis. Pediatr Infect Dis J 18:816-822

Delouvois J (1994) Acute bacterial meningitis in the newborn. J Antimicrob Chemother 34(Suppl A):61-73

Delouvois J, Blackbourn J, Hurley R et al (1991) Infantile meningitis in England and Wales: a two year study. Arch Dis Child 66(5):603-607

Elizabeth AM, Guilaine K et al (2013) Neonatal sepsis due to coagulase-negative staphylococci. Clin Dev Immunol. doi:10.1155/2013/586076

Francis BM, Gilbert GL (1992) Survey of neonatal meningitis in Australia: 1987-1989. Med J Aust 156(4):240-243

Gebremariam A (1998) Neonatal meningitis in Addis Ababa: a 10-year review. Ann Trop Paediatr 18(4):279-283

Grupo de Hospitales Castrillo (2002) Neonatal meningitis: epidemiological study of the Grupo de Hospitales Castrillo. An Esp Pediatr 56:493-496

Harmony PG, Anthony MM, Michael CC et al (2006) Neonatal meningitis: what is the correlation among cerebrospinal fluid cultures, blood cultures, and cerebrospinal fluid parameters? Pediatrics 117(4):1094-1100

Harvey D, Holt D, Bedford H (1999) Bacterial meningitis in the newborn: a prospective study of mortality and morbidity. Semin Perinatol 23:218-225

Heath PT, Nik Yuoff NK, Baker CJ (2003) Neonatal meningitis. Arch Dis Child Fetal Neonatal Ed 88:F173-F178. doi:10.1136/fn.88.3.F173 
Hristeva L, Booy R, Bowler I, Wilkinson AR (1993) Prospective surveillance of neonatal meningitis. Arch Dis Child 69(1):14-18. doi:10.1136/ adc.69.1_Spec_No.14

Laving AMR, Musoke RN, Wasunna AO, Revathi G (2003) Neonatal bacterial meningitis at the newborn unit of Kenyatta National Hospital. East Afr Med J 80(9):456-462

Luzia PAS, Laura GC, Fernanda Q, Camila VN, Rita L (2007) Prevalence of newborn bacterial meningitis and sepsis during the pregnancy period for public health care system participants in Salvador, Bahia, Brazil. Braz $\rfloor$ Infect Dis 11(2):272-276

Matthijs CB, Allan RT, Diederik VB (2010) Epidemiology, diagnosis, and antimicrobial treatment of acute bacterial meningitis. Clin Microbiol Rev 23(3):467-492. doi:10.1128/CMR.00070-09

May M, Daley AJ, Donath S, Isaacs D (2005) Early onset neonatal meningitis in Australia and New Zealand, 1992-2002. Arch Dis Child Fetal Neonatal Ed 90:F324-F327

Meenakshi R, Aaron JU, Laura CS, Jennifer CM, Fred, Orin SL (2009) Sequelae due to bacterial meningitis among African children. A systematic literature review. BMC Med 7:47

Michael GS, Anne DW (1985) Meningitis: describing the community health problem. Am J Public Health 75(5):550-552

Mohammad HA, Farajzadeh SA, Dehdashtian M (2010) Eleven-year study of causes of neonatal bacterial meningitis in Ahvaz Iran. Pediatr Int 52(3):463-466. doi:10.1111/j.1442-200X.2010.03107.x
Mueller JE, Gessner BD (2009) A hypothetical explanatory model for meningococcal meningitis in the African meningitis belt. Int J Infect Dis 14:553-559

Olivia S, Dean BE, Jeremry SF et al (2014) Bacterial meningitis in Malawian infants < 2 months of age. Pediatr Infect Dis J 33(6):560-565. doi:10.1097/ INF.00000000000000210

Osrin D, Vergnano S, Costello A (2004) Serious bacterial infections in newborn infants in developing countries. Curr Opin Infect Dis 17:217-224

Pablo FP, Joel D, Marion L et al (2007) Bacterial imprinting of the neonatal immune system: lessons from maternal cells? Pediatrics 119:e724-e732. doi:10.1542/peds.2006-1649

Polin R, Harris M (2001) Neonatal bacterial meningitis. Semin Neonatol 6:157-172 Pong A, Bradley JS (1999) Bacterial meningitis and the newborn infant. Infect Dis Clin N Am 13:712-733

Saleem B, Naveen S, Michael P (2014) Immune responses in neonates. Expert Rev Clin Immunol 10(9):1171-1184. doi:10.1586/1744666X.2014.942288

Stevens JP, Eames M, Kent A, Halket S, Holt D, Harvey D (2003) Long term outcome of neonatal meningitis. Arch Dis Child Fetal Neonatal Ed 88(3):F179-F184

Synnott MB, Morse DL, Hall SM (1994) Neonatal meningitis in England and Wales: a review of routine national data. Arch Dis Child 71:75-80

The WHO Young Infant Study Group (1999) Bacterial etiology of serious infections in young infants in developing countries: results of a multicenter study. Pediatr Infect Dis J 18:17-22

\section{Submit your manuscript to a SpringerOpen ${ }^{\circ}$ journal and benefit from:}

- Convenient online submission

- Rigorous peer review

- Immediate publication on acceptance

- Open access: articles freely available online

- High visibility within the field

- Retaining the copyright to your article

Submit your next manuscript at $\boldsymbol{\nabla}$ springeropen.com 